\title{
Control Management for Three Renewable Energy Generators and Diesel Generator for Rural/Remote Sites
}

\author{
Wadah Aljasim and Walaa Hussein
}

\begin{abstract}
This paper shows a control method for three renewable energy generators (Wind, Solar, batteries bank generators) and diesel generator via PLC producing the required electrical supply for the remote and rural sites.
\end{abstract}

Index Terms - Wind, Solar, batteries bank generators, diesel generator and PLC.

\section{INTRODUCTION}

Solar power is the conversion of sunlight into electricity, either directly using photovoltaics (PV), or indirectly using concentrated solar power. Concentrated solar power systems use lenses or mirrors and tracking systems to focus a large area of sunlight into a small beam. Photovoltaic cells convert light into an electric current using the photovoltaic effect [1]. The International Energy Agency projected in 2014 that under its "high renewables" scenario, by 2050, solar photovoltaics and concentrated solar power would contribute about 16 and 11 percent, respectively, of the worldwide electricity consumption, and solar would be the world's largest source of electricity. Most solar installations would be in China and India [2]. Photovoltaics were initially solely used as a source of electricity for small and medium-sized applications, from the calculator powered by a single solar cell to remote homes powered by an off-grid rooftop PV system. As the cost of solar electricity has fallen, the number of grid-connected solar PV systems has grown into the millions and utility-scale solar power stations with hundreds of megawatts are being built. Solar $\mathrm{PV}$ is rapidly becoming an inexpensive, low-carbon technology to harness renewable energy from the Sun. The current largest photovoltaic power station in the world is the 850 MW Long yangxia Dam Solar Park, in Qinghai, China.

Commercial concentrated solar power plants were first developed in the 1980s. The 392 MW Ivanpah installation is the largest concentrating solar power plant in the world, located in the desert of California. Many industrialized nations have installed significant solar power capacity into their grids to supplement or provide an alternative to conventional energy sources while an increasing number of less developed nations have turned to solar to reduce dependence on expensive imported fuels. Long distance transmission allows remote renewable energy resources to

Submitted on February 27, 2021

Published on March 24, 2021.

Wadah Aljasim, Consultant, Sydney, Australia.

(e-mail: wadaha@yahoo.com)

Walaa Hussein, Lecturer of Iraq University Collage, Basra, Iraq.

(e-mail: Walaahussein613@gmail.com) displace fossil fuel consumption. Solar power plants use one of two technologies:

- Photovoltaic (PV) systems use solar panels, either on rooftops or in ground-mounted solar farms, converting sunlight directly into electric power.

- Concentrated solar power (CSP, also known as "concentrated solar thermal") plants use solar thermal energy to make steam that is thereafter converted into electricity by a turbine.

Fig. 1 shows schematics of a grid-connected residential $\mathrm{PV}$ power system.

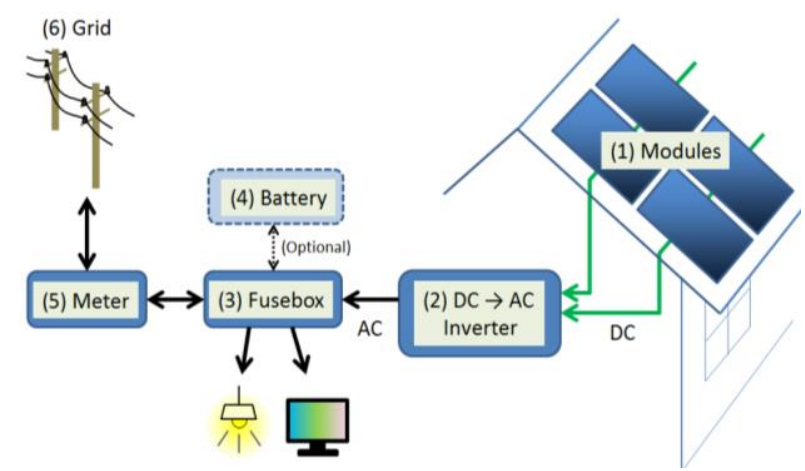

Fig. 1. Schematics of a grid-connected residential PV power system [3].

A solar cell, or photovoltaic cell (PV), is a device that converts light into electric current using the photovoltaic effect. In 1931, the German engineer Bruno Lange developed a photo cell using silver selenite in place of copper oxide [4]. The array of a photovoltaic power system, or PV system, produces direct current (DC) power which fluctuates with the sunlight's intensity. For practical use this usually requires conversion to certain desired voltages or alternating current $(\mathrm{AC})$, through the use of inverters [3]. Multiple solar cells are connected inside modules. Modules are wired together to form arrays, then tied to an inverter, which produces power at the desired voltage, and for AC, the desired frequency/phase [3]. Many residential PV systems are connected to the grid wherever available, especially in developed countries with large markets [5]. In these grid-connected PV systems, use of energy storage is optional.

\section{Proposed Control Method}

Fig. 2 shows the flow chart for the renewable energy system control method. In general, there is a preparation and process in this flow chart, the preparation works if the wind is strong enough. For example, if the wind is good 
enough, then the answer is (yes), which means the reading of wind anemometer (analogue input) passes to the PLC to be processed there. If the reading of the wind anemometer is a weak, then the answer is (no), as a result it will go to another way, to another decider as shown in the flow chart. The process unit (rectangular shape) has no decision just process the inputs to pass them to the next stage. It starts when the renewable energy resources like wind or sunlight or both are strong enough to activate the related contactor.

The wind resource is red, if the wind speed is strong enough then the wind anemometer indicates that wind speed sending it to the PLC, in addition to the wind speed (analogue input), there are another related condition related to each renewable energy generator, battery bank resource, and diesel generator (like start, stop push button, emergency switch, etc.), if all these conditions are on, the status of these conditions will transfer to the PLC, as a result the PLC activates the wind contactor to tum it on. The feeding voltage, which is supplied by wind generator passed over to the output $\mathrm{AC}$ bus bar.

Wind generator produces $\mathrm{AC}$ voltage feeding this voltage to the rectifier to change the $\mathrm{AC}$ voltage into $\mathrm{DC}$ voltage, then supplying the battery to charge it up, the battery bank voltage is regulated by regulator to keep the voltage within 12 volts, in this way the voltage which is generated by wind generator can be control even if the wind varies. Passing this DC voltage to an inverter to convert the DC voltage to $\mathrm{AC}$ voltage to feed the wind contactor, then it supplies the $\mathrm{AC}$ bus bar. If the sunlight is good enough (sunny day), then solar sensor indicates the light and transfer this indication to the PLC, in addition to the solar sensor (analogue input), there are another related condition related to each renewable energy generator, battery bank resource, and diesel generator (like start, stop push button, emergency switch, etc.), if all these conditions are on, the status of these conditions will transfer to the PLC, as a result the PLC activates the solar contactor to turn it on, then the feeding voltage from the solar generator passed over to the DC bus bar.

For green power optimization the control method has been designed so that if wind or sun or both available then it will feed the output AC bus bar. If the sunlight and wind are not good enough (nighttime and not windy), and the voltage of the battery bank is good enough, and all the related conditions to the battery bank resource are on, then the status of the analogue sensor (analogue input) and all the related conditions will image to the PLC, as a result the PLC activates the battery bank contactor to pass the feeding DC voltage from the battery bank resource to the DC voltage bus bar.

If the condition (no wind and nighttime, and the voltage of battery bank resource is not good enough) is available, then these conditions are imaged in the PLC, as a result it causes the LPG or diesel contactor to activate to pass over the feeding AC voltage to the output AC bus bar. Test mode for the diesel or LPG generator means that even if the wind or the sunlight, or the voltage for the battery bank are good enough, then we could start the diesel generator by pressing the emergency switch in each renewable energy generator and battery bank resource, this means these resources will stop to start the diesel generator to check the diesel generator.

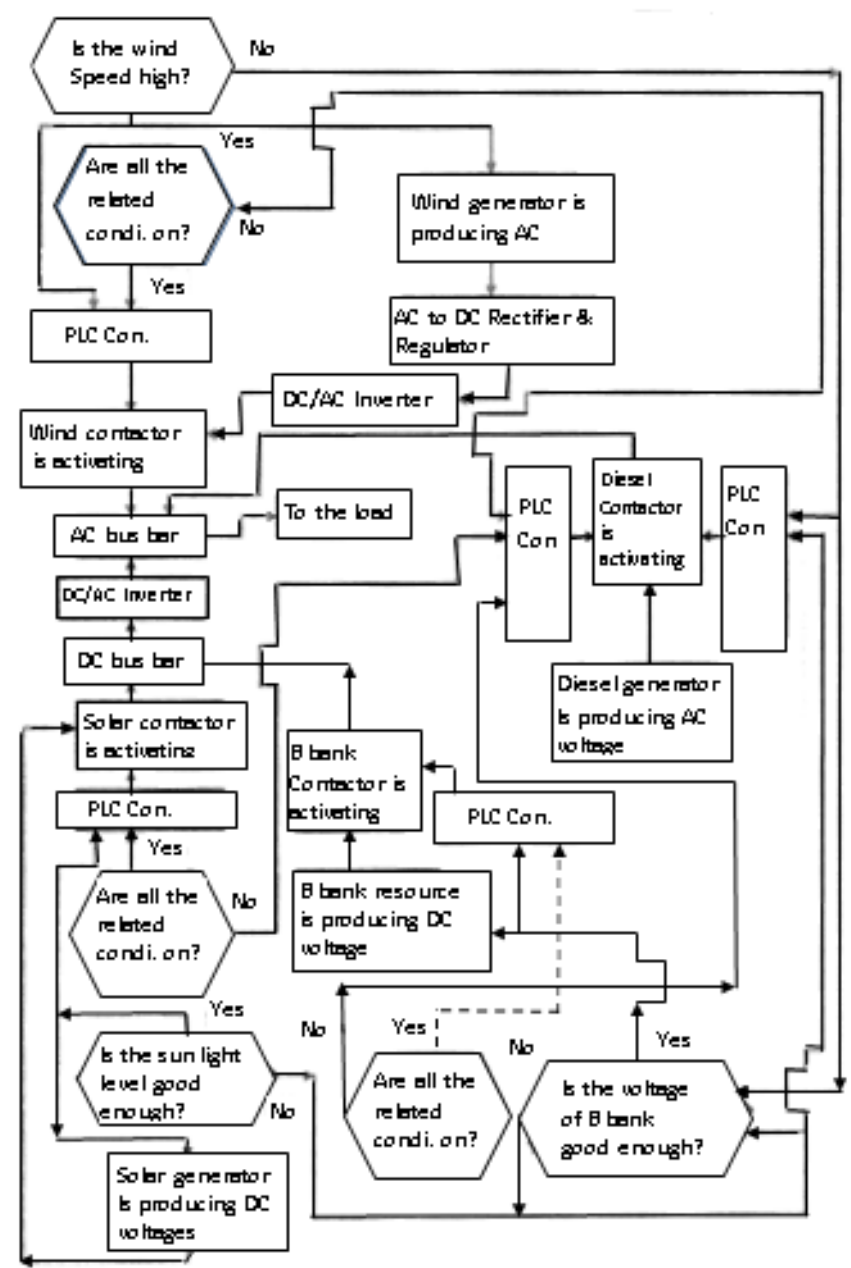

Fig. 2. Renewable energy system's control method.

Fig. 3 shows the connection of the analogue sensors to slot 3. NI4 the analogue input card consists of 4 channels; three channels are used while the fourth channel is empty for future use such as wind generator voltage analogue sensor or diesel generator voltage sensor. Starting with the first analogue sensor, the wind anemometer device consists of two parts, wind probe and wind anemometer controller, which is connected to the first channel. The wind controller has been fed by $240 \mathrm{~V} \mathrm{AC}$, internally this $240 \mathrm{VAC}$ voltage inside the controller will be converted into $24 \mathrm{VDC}$, the positive terminal of the controller connects to the positive terminal of the wind probe, the negative terminal of the wind probe connects to the positive terminal of the first channel. The negative terminal of the first channel connects to the negative terminal of the controller. The same method has been used for second and third sensors. 


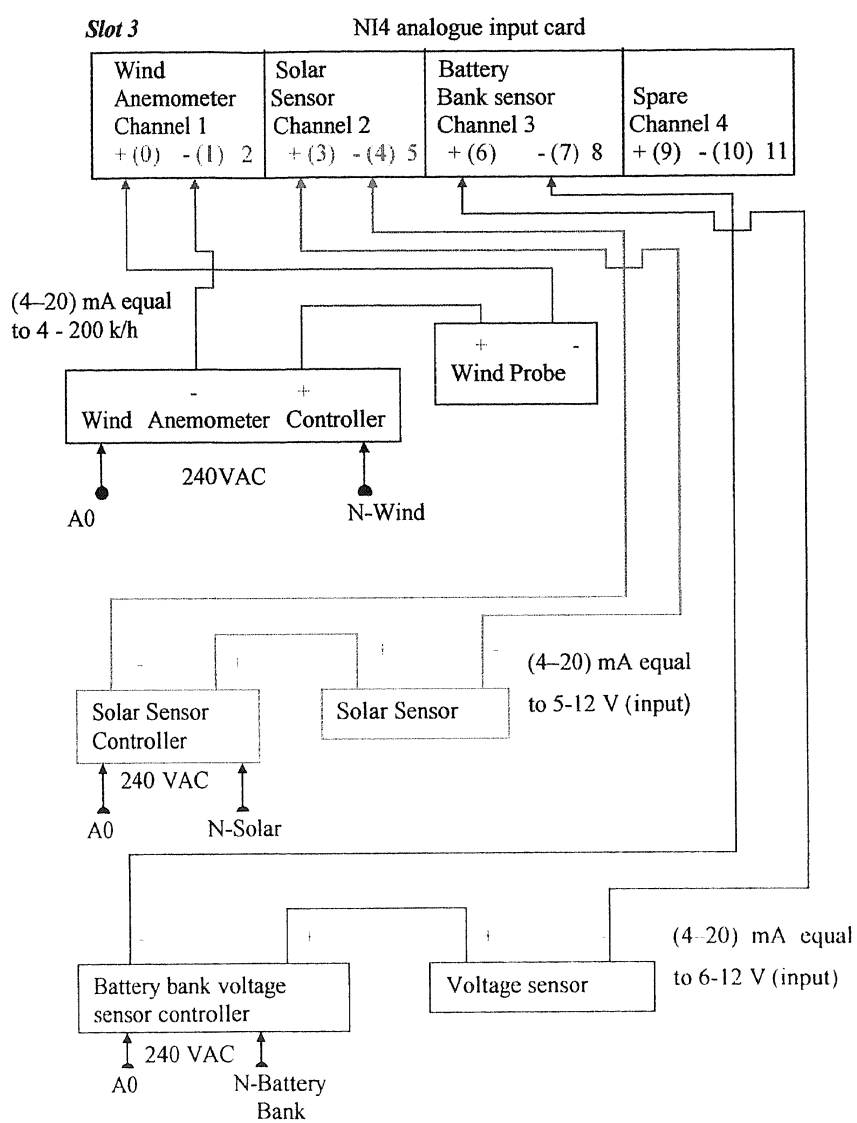

Fig. 3. Connection of analogue sensors to PLC.

Fig. 4 shows that in the normal operation of the wind generator $b 3 / 11$ and $b 3 / 12$ both deactivated (under range value and over range value), then SCL instruction scales the reading from the wind anemometer N9: 15 (source) and transfers it to the destination N9:0. SCL it does the scaling depending on the rate and offset between the scaled range and input value of the wind anemometer. The calculation for finding the rate and offset can be achieved by using the linear relationship as shown in figure 5 between the scaled range in $\mathrm{Km} / \mathrm{h}$ and input value, the formulas below found from this linear relationship. Slope $=$ scaled range $/$ input range.

Off set $=$ min scale $-(\min$ input value $\times$ slope $)$.

Rate $=($ scaled range $/$ input range $) \times 10000$.

The calculation for wind generator for the value between $4 \mathrm{Km} / \mathrm{h}$ to $200 \mathrm{Km} / \mathrm{h}$ is:

$$
\text { Slope }=(200-4) /(16384-3277)
$$

$$
\text { Offset }=4-(3277 \times(196 / 13107))=-45.0037,
$$

because the integer file accepts integer value so the offset value $=-45$.

$$
\text { Rate }=(196 / 13107) \times 10000=149.53,
$$

Integer file accepts integer value only, so rate $=150$.

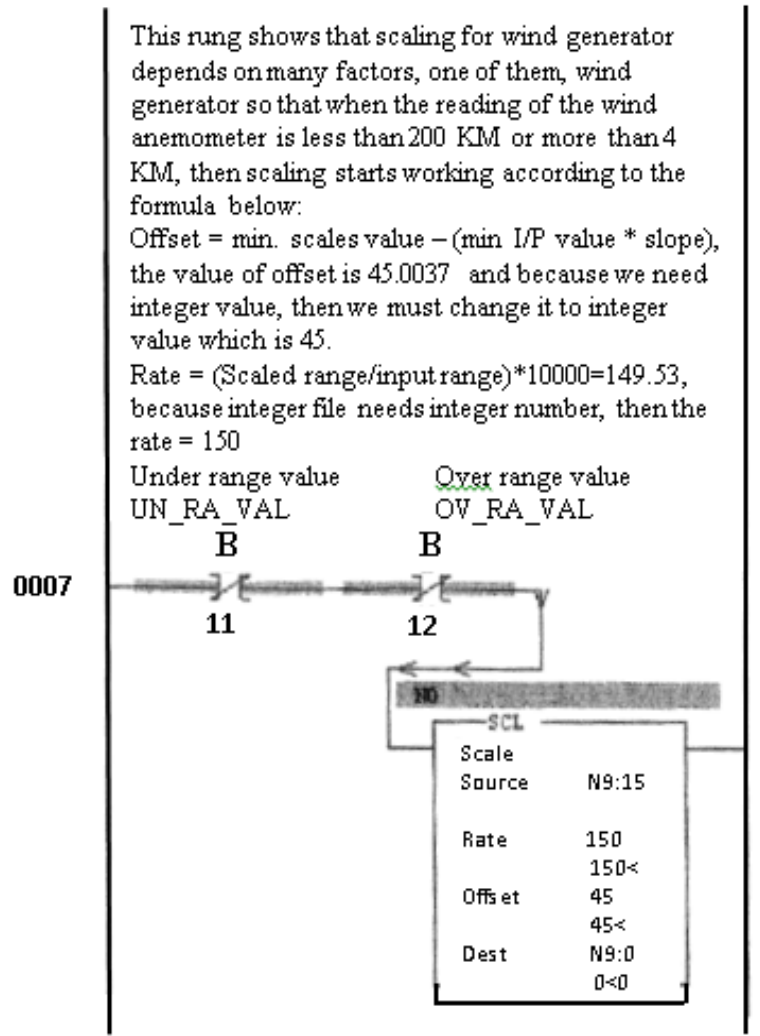

Fig. 4. Scaling the input of the wind anemometer.

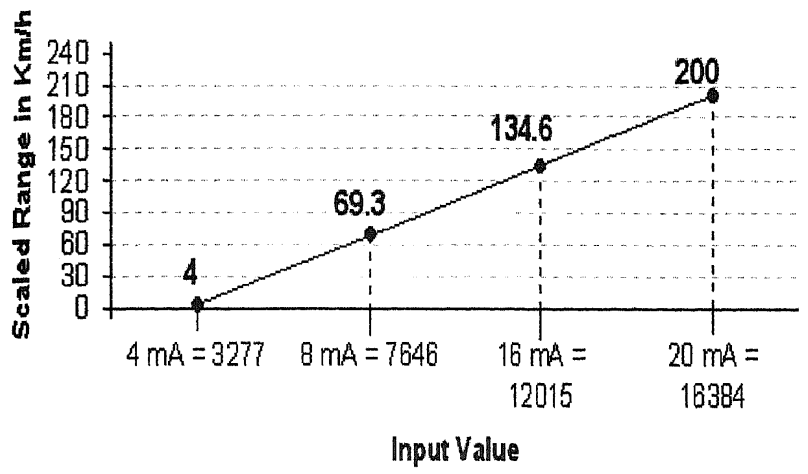

Fig. 5. Scaling graph of wind anemometer.

After calculating the analogue input (4-20) $\mathrm{mA}$ representing the scaled range (4-200) $\mathrm{Km} / \mathrm{h}$. Enter the values of offset, rate in the SCL Instruction so that it start converts the analogue reading from wind anemometer into processor. The difference of (4-20) $\mathrm{mA}$ method from other measurement methods like $0-10 \mathrm{~V}$. The choice of current or voltage is usually dependent on the supply signal from the device, a current signal tends to be less likely to be corrupted by electrical noise - a current signal needs to be generated where electrical fields may create a current signal of their own. The reason it started from (4-20) not from (020) $\mathrm{mA}$, the choice of current ranges is a user defined selection once more and for many years 4-20 mA has been the default standard. This selection may also allow for an undercurrent signal and give a better resolution by minimizing intervals over the range. 


\section{CONCLUSIONS}

The development of the control method for two renewable energy generators, battery bank resource and backup diesel are helping to produce a fuel free electricity generating system; this combination renewable energy systems and diesel generator reduce the dependency on fossil fuel for electricity generation. This also reduces global warming and leads to a clean environment. An enhanced control method for a renewable energy system can be achieved by using three analogue sensors. Sensor used for the wind contactor, another sensor used for solar contactor, and the last sensor used for battery bank contactor. The Allen Bradley PLC (SLC 500) and RSLogix 500 have been described as the employed hardware and software, respectively. The Developed system can be summarized by: The natural resources like wind, sunlight and the battery bank will activate their respective contactor depending on their specified conditions. Two types of inputs have been used, digital inputs like push buttons, switches, emergency switches, and analogue inputs like wind anemometer, solar sensor, and voltage sensor for battery bank.

\section{REFERENCES}

[1] Department of Energy, "Energy Sources: Solar". Retrieved 19 April 2011.

[2] International Energy Agency (2014). "Technology Roadmap: Solar Photovoltaic Energy" (PDF). IEA. Archived from the original on 7 October 2014. Retrieved 7 October 2014.

[3] Lewis Fraas and Larry Partain, Solar Cells and their Applications Second Edition, 2010, ISBN 978-0-470-44633-1, Section10.2.

[4] Corporation, Bonnier, "Magic Plates, Tap Sun for Power". Popular Science, June 1931. Retrieved 19 April 2011.

[5] "Trends in Photovoltaic Applications Survey report of selected IEA countries between 1992 and 2009, IEA-PVPS". Retrieved 8 November 2011. 